DOI: https://doi.org/10.24867/05KG01Deuric

\title{
STANJE PREMJERA NA TERITORIJI POLITIČKIH OPŠTINA VLASENICA I HAN PIJESAK
}

\section{STATE SURVEY OF THE POLITICAL TERRITORY OF THE VLASENICA AND HAN PIJESAK MUNICIPALITY}

\author{
Aleksandra Deurić, Goran Marinković, Fakultet tehničkih nauka, Novi Sad
}

\section{Oblast - GEODEZIJA I GEOMATIKA}

Kratak sadržaj - U ovom radu je izvršena analiza stanja premjera i katastra u opštinama Vlasenica i Han Pijesak u Republici Srpskoj. Pored opšte analize, izvršena je $i$ uporedna analiza za ove dvije opštine na osnovu čega su doneseni određeni zaključci koji prikazuju nivo razvoja $i$ probleme premjera i katastra u obje opštine.

Ključne reči: Katastar nepokretnosti, Premjer, Vještačenje

Abstract - In this paper an analysis of the state of survey and cadastre in the municipalities of Vlasenica and Han Pijesak in the Republika Srpska was conducted. In addition to the general analysis, a comparative analysis was carried out for these two municipalities, and on the basis of which certain conclusions were drawn showing the level of development and problems of survey and cadastre in both municipalities.

Keywords: Cadastre, Survey, expertize

\section{UVOD}

Zahvaljujući mnogim pronađenim dokazima, poznato je da potreba mjerenja zemljišta $u$ svrhu evidentiranja podataka vezanih za njega, seže u daleku prošlost. Još iz predistorije civilizacije pronađeni su dokazi koji nam svjedoče o potrebi plemenskih zajednica, a kasnije država, da se izrade planovi pripadajućih područja. Svjest o važnosti ovakve vrste evidencije je u različitim istorijskim periodima bolje ili slabije dokazana, ali se svakako može zaključiti da je kontinuirana i rano shvaćena. U ovim istorijskim činjenicama pronalazimo začetak razvoja katastra nepokretnosti, u smislu kakvog ga mi danas poznajemo.

Na prostoru Bosne i Hercegovine geodetska djelatnost počinje dosta rano $u$ poređenju sa drugim evropskim državama. Prve geodetske mreže koje se zasnivaju na matematičkom premjeru nastaju za vrijeme okupacije od strane Austrougarske monarhije. Tada je pod rukovodstvom vojnih topografa, katastarski premjer cjelokupne okupirane teritorije izvršen za samo četiri godine, od 1880. do 1884. godine. To je bio prvi sistematski premjer cijele teritorije $\mathrm{BiH}$. Dotadašnja evidencija na nepokretnostima je počivala na tapijskom sistemu.

\section{NAPOMENA:}

Ovaj rad proistekao je iz master rada čiji mentor je bio dr Goran Marinković, docent.
Osnivanjem prve moderne evidencije podataka o zemljištu i objektima, od strane Austrougarske može se reći da počinje period razvoja geodetske djelatnosti u $\mathrm{BiH}$.

Predmet istraživanja ovog rada jeste istorijski razvoj geodetske djelatnosti na teritoriji Bosne i Hercegovine, sa posebnim akcentom na opštine Vlasenica i Han Pijesak. Glavni cilj istraživanja jeste da se utvrdi kvalitet i upotrebljivost starog austrougraskog premjera $\mathrm{u}$ današnjim uslovima kao i da se kroz analizu grešaka koje evidentno postoje u podacima premjera i bazama katastra nepokretnosti, daju smjernice za ažurnije i efikasnije održavanje premjera i katastra nepokretnosti.

\section{ISTORIJSKI RAZVOJ GEODETSKE DJELATNOSTI U BOSNI I HERCEGOVINI}

U ovom poglavlju opisana su ključna razdoblja razvoja geodetske službe u Bosni i Hercegovini. Prvi period se vezuje za upravu Osmanske carevine od XV do XIX vijeka odakle ujedno potiču i prve zemljišne evidencije $u$ BiH.

Nakon toga slijedi period okupacije i aneksije BiH od strane Austrougarske monarhije, kada je izvršen premjer i uspostavljen katastar zemljišta, zemljišna knjiga, izgrađena saobraćajna infrastruktura itd.

Poslednje ključno razdoblje se vezuje za period uprave stare i nove Jugoslavije gdje su primjenom modernijih metoda uspostavljene geodetske mreže, izveden novi premjer i uspostavljene nove evidencije o zemljištu a takođe izrađene su i veoma kvalitetne karte.

\section{KATASTAR NEPOKRETNOSTI}

Katastar nepokretnosti je javna knjiga koja predstavlja osnovnu evidenciju o nepokretnostima i pravima na njima. Prava na nepokretnostima stiču se, prenose, ograničavaju i prestaju upisom u katastar nepokretnosti.

Katastar nepokretnosti sastoji se od:

- Elaborata premjera;

- Zbirke isprava;

- Baze podataka katastra nepokretnosti.

Katastar nepokretnosti kao osnov sistema vlasništva, predstavlja prioritetni interes svake Državne uprave jer sadrži relevantne informacije koje omogućuju uvid u njenu najvrijedniju aktivu - prostor i nepokretnosti na njenoj teritoriji [3]. Katastar nepokretnosti kao osnov sistema vlasništva predstavlja i jedan od stubova savremene civilizacije. Kao takav on mora biti tretiran kao opšti interes i njegovo održavanje i unaprjeđenje mora da bude sistematično, kontinuirano i u funkciji ciljeva svih građana i Države. 
Zakonom o državnom premjeru i katastru propisan je postupak kojim se sa ranije važećih evidencija prelazi na katastar nepokretnosti kao i jedinstvenu evidenciju [1].

\section{STANJE PREMJERA U OPŠTINI VLASENICA}

\subsection{Prvi premjer}

$\mathrm{Na}$ području opštine Vlasenica prva potpuna evidencija zemljišta uspostavljena je na osnovu premjera koji je izvršila Austrougarska. Premjer na području ove opštine započeo je u proljeće 1882. godine, a cjelokupne radove katastarskog premjera su obavljali brojni stručnjaci iz reda Austrougarske vojske, na čijem čelu je bio direktor Mayer Wilhelm.

Katastar je izrađen u rekordno kratkom vremenu od četiri godine i koncipiran je tako da istovremeno zadovolji vojne i upravne potrebe monarhije. Katastarski planovi su odrađeni u razmjeri 1:6250. Izuzetak su predstavljali planovi gradskog i gusto naseljenog područja koji su rađeni u razmjerama 1:3125, 1:562.5, 1:781.25. Na ovim planovima je prikazana samo horizontalna predstava terena, tj. zemljište i objekti na zemljištu.

$\mathrm{Na}$ osnovu izvršenog premjera uspostavljen je katastar zemljišta. Katastar, pored katastarskih planova sadrži popis zemljišta sa naznakom vrste zemljišta, katastarske klase i popisom vlasnika parcela i objekata.

\subsection{Omeđavanje katastarskih opština}

Omeđavanje predstavlja postupak obnavljanja međnih tačaka, na osnovu podataka važećeg premjera, tj. premjera koji je zvanično validan u evidenciji Republičkog geodetskog zavoda.

Omeđavanje katastarskih opština na području Opštine Vlasenica vršeno je u toku 1977. godine nakon izvršenog aerofotogrametrijskog snimanja. Omeđavanje je izvršeno u 18 katastarskih opština na području Opštine Vlasenica. Kako bi se sačuvali prikupljeni podaci uporedo sa omeđavanjem rađeni su i zapisnici omeđavanja, te postoji 18 knjiga zapisnika i isto toliko knjiga koje sadrže spiskove površina parcela.

\subsection{Državni premjer}

Kako bi se prevazišao austrougraski premjer, 1953. godine počeo se izvoditi novi premjer za potrebe prostornog planiranja, projektovanja i građenja, u skladu sa Uredbom o osnivanju nadležnosti Geodetske uprave NR BiH .

Primjenom savremenih metoda premjeravanja (aerofotogrametrija) Bosne i Hercegovine, do kraja 1991. godine obavljen je posao premjera na oko $92 \%$ teritorija, i na tim osnovama uspostavljen katastar nepokretnosti na oko 50\% teritorija Bosne i Hercegovine. Radovi su izvršavani prema propisima tadašnje Savezne geodetske uprave, te Geodetske uprave Bosne i Hercegovine. Radove premjera izvodio je "Georad", sadašnji "Geodetski zavod Bosne i Hercegovine". Podaci obavljenog premjera bili su obimni i sadržajni te je samim tim bilo potrebno mnogo vremena za obradu istih.

\subsection{Analiza stanja premjera na teritoriji političke opštine Vlasenica}

Opštinu Vlasenica čini 18 katastarskih opština, i to 15 katastarskih opština seoskog tipa i 3 katastarske opštine gradskog tipa. Digitalni katastarski plan je urađen za 10 katastarskih opština, dok za preostalih 8 katastarskih opština još uvijek ne postoji digitalni katastarski plan (slika 1). Kao tehnički normativ korišten je Pravilnik o Digitalnom geodetskom planu [2].

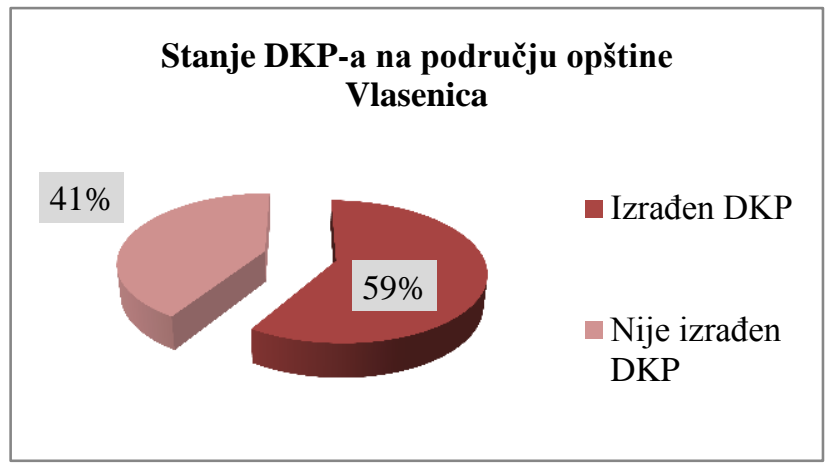

Slika 1. Stanje DKP-a и и političkoj opštini Vlasenica

Pri analizi stanja premjera neophodno je osvrnuti se na tačnost dobijenih podataka i izvršenog premjera.

Uvidom u službenu evidenciju područne jedinice Vlasenica i analizom postojeće dokumentacije (terenske skice, tahimetrijski zapisnici, manuali, trigonometrijski obrasci itd.) može se zaključiti da su na kvalitet premjera, odnosno na tačnost dobijenih podataka uticali sledeći faktori :

- Tačnost državne geodetske osnove;

- Tačnost snimanja detalja prvobitnog premjera;

- Tačnost održavanja premjera;

- Greške kartiranja i izrade analognih katastarskih planova;

Kao faktori kvaliteta dobijenih podataka premjera mogu se izdvojiti vještačenja i zahtjevi za ispravku greške. Što se tiče vještačenja i supervještačenja na teritoriji opštine Vlasenica, supervještačenja u posmatranom periodu od 2014. do 2018. godine nije bilo, a broj vještačenja varira od godine do godine (slika 2).

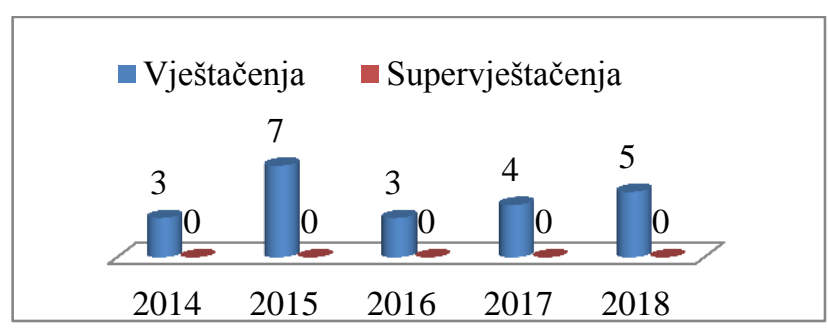

Slika 2. Broj vještačenja i supervještačenja po godinama

Vještačenja i supervještačenja, kao dokazno sredstvo u parničnim i krivičnim postupcima imaju veliku ulogu prilikom donošenja odluka u sudskim i drugim postupcima, pri čemu nalaz i mišljenje vještaka predstavljaju jedini prihvatljiv dokaz za donošenje pravičnih odluka pri rješavanju komflikta između strana u postupku pred kojima se rešavaju sporovi.

Glavni krivci za pojavu vještačenja i supervještačenja su nesavršenstvo premjera, greške, nedostaci i propusti u premeru, odnosno održavanju premjera.

Kada je riječ o zahtjevima za ispravku greške u područnoj jedinici Vlasenica najčešće se odnose na greške nastale zbog pogrešno izračunate površine i oblika katastarskih parcela, pogrešno upisane spratnosti objekata, pogrešno upisane površine posebnih dijelova, greške pogrešne 
adrese nosioca prava i slično. Ove greške se otkrivaju u procesu izrade DKP-a, sravnavanje površina se vrši na novi premjer jer se on po važećim propisima uzima kao tačan.

$\mathrm{Na}$ osnovu dobijenih podataka iz katastarskog operata na području opštine Vlasenica, broj predmeta za ispravku greške od 2014. godine, zaključno sa prvom polovinom 2018. godine je 389 (slika 3). Zahtjevi se uglavnom odnose na ispravku granica katastarske parcele ili na promjenu oblika katastarske parcele.

\begin{tabular}{|cccccc|}
\hline \multicolumn{5}{|c|}{ Broj zahtjeva za ispravku greške } \\
2014 & 2015 & 2016 & 2017 & 2018 \\
& & & & & \\
165 & 92 & 72 & 39 & 21 \\
\hline 1 & 2 & 3 & 4 & 5 \\
\hline
\end{tabular}

Slika 3. Broj zahtjeva za ispravku greške

\section{STANJE PREMJERA U OPŠTINI HAN PIJESAK}

\subsection{Prvi premjer}

Prvi premjer na području opštine Han Pijesak sproveden je 1885. godine od strane Austrougarske uprave. Izvedeni premjer je grafički i odlikuje ga znatno zadovoljavajuća tačnost za pomenuti period. Snimanje je vršeno u razmjerama 1:2880 i 1:2500, u zavisnosti od važnosti dijela opštine koji se snima, ali i same pristupačnosti. Premjer karakteriše poliedarska kartografska projekcija kao i ostatak BiH.

\subsection{Novi premjer opštine Han Pijesak}

U martu 2008. godine na području opštine Han Pijesak započet je projekat koji se odnosio na uspostavljanje katastarskog premjera za 11 katastarskih opština u kojima je na snazi bio popisni katastar. Dvije godine kasnije, u decembru 2010. godine preduzeće Geoinženjering d.o.o. je Republičkoj upravi za geodetske i imovinsko pravne poslove iz Banja Luke predalo rezultate radova premjera dijela opštine Han Pijesak.

Projektom je izvršen premjer sledećih katastarskih opština: Crna Rijeka, Japaga, Kusače, Malo Polje, Mrkalji 1, Mrkački 2, Pjenovac, Podžeplje, Pogled, Rečice i Rijeke. Završetkom ovog Projekta još 30803 hektara nepremjerenog područja opštine Han Pijesak je dobilo novi, moderan premjer.

Novi premjer je izvršen aero-fotogrametrijskom metodom, sa izuzetkom gradskog dijela, gdje su korištene klasične metode, polarna i ortogonalna metoda.

Cilj realizovanog projekta bio je izrada novog, modernog digitalnog katastra nepokretnosti za dio opštine u kojoj je na snazi tzv. popisni katastar uspostavljen pedesitih godina prošlog vijeka.

\subsection{Analiza stanja premjera na teritoriji političke opštine Han Pijesak}

Politička opština Han Pijesak sadrži 12 katastarskih opština od kojih je jedna gradskog tipa a preostale su seoskog tipa. Kao što je prikazano u nastavku digitalni katastarski plan je završen za 10 katastarskih opština u Han Pijesku dok je za preostale dvije izrada DKP-a u toku. Tačnije izrada DKP-a za katastarsku opštinu Pjenovac je u završnoj fazi.
DKP za katastarske opštine je rađen na osnovu podataka aerofotogrametrijskog snimanja, dok su za katastarske opštine Crna Rijeka i Malo Polje korišteni i skenirani stari planovi.

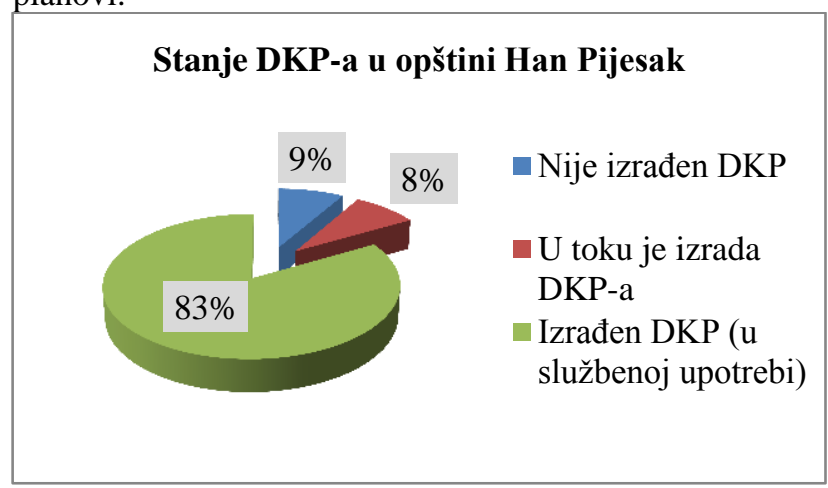

Slika 4. Stanje DKP-a u u političkoj opštini Han Pijesak

Što se tiče vještačenja i supervještačenja, na području opštine Han Pijesak nije bilo supervještačenja u periodu od 2014. do 2018. godine, dok broj vještačenja varira od godine do godine, te ih od 2014. godine do sad ima ukupno 20.

Vještačenja se rješavaju brzo i u zakonskom roku. Procenat rješenosti je trenutno $91 \%$ i ima trend vremenskog smanjenja, što direktno zavisi od prirode predmeta koji se rješavaju i učešća stranki u postupku u smislu kompletiranja dokumentacije (slika 5).

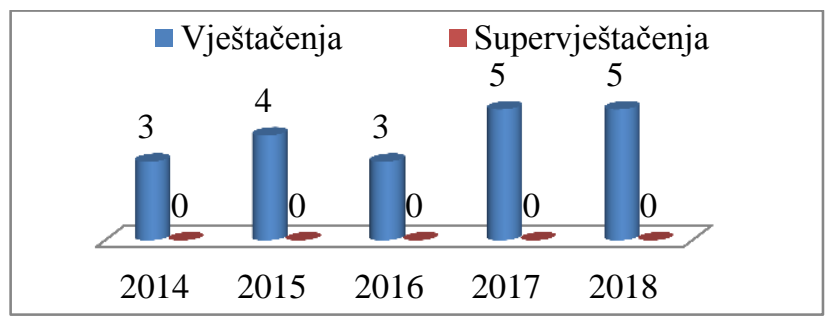

Slika 5. Broj vještačenja i supervještačenja po godinama

Analizom završenih predmeta vještačenja može se zaključiti da su najčešći uzroci za nastanak konflikta između suprotstavljenih strana $u$ sporovima sledeći: netačni i nepouzdani podaci koji se odnose na ograničenu tačnost državne geodetske osnove, zatim greške i propusti u održavanju premjera, greške kartiranja i formiranja katastarskih parcela, kao i greške upisa vlasništva na nepokretnostima.

Kada je riječ o zahtjevima za ispravku greške, broj predmeta od 2014. godine, zaključno sa prvom polovinom 2018. godine je 215. Zahtjevi se uglavnom odnose na ispravku granica katastarske parcele ili na promjenu oblika katastarske parcele.

Raspored zahtjeva po godinama prikazan je u nastavku (slika 6).

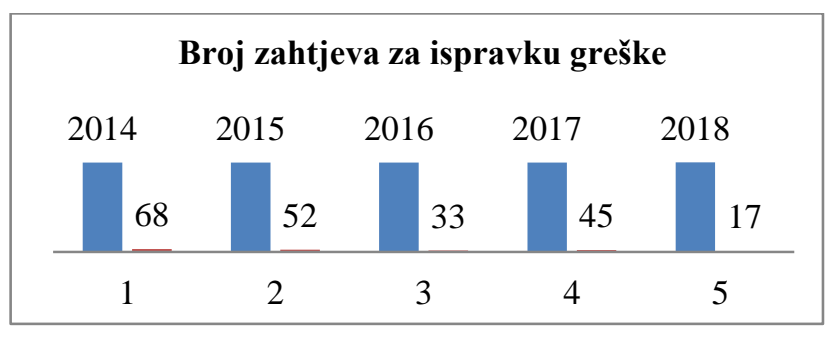

Slika 6. Broj zahtjeva za ispravku greške 


\section{DISKUSIJA}

Kroz početna poglavlja ovog rada dat je osvrt na istorijsku građu katastarskog tkiva na kom počiva današnji katastarski sistem. Uvidom u istorijski razvoj katastra, možemo zaključiti da su različiti državni sistemi, imali različite pristupe kontroli nad podacima o nepokretnosima i nad pravima nad njima. Naravno, akcenat je stavljen na period kada su nastajali podaci koji se i danas održavaju, kao i na referentne mreže, način njihovog nastanka i opis stanja u kome se nalaze.

Što se tiče trenutnog stanja $u$ posmatranim opštinama možemo reći da su tradicionalni katastarski sistemi dugo uživali ugled zbog svoje pouzdanosti, dobro definisanih procesa i opšte poznate garancije sigurnosti privatnog vlasništva. Međutim, tehnološki napredak, društvene promjene, globalizacija i rastuća međupovezanost poslovnih odnosa $\mathrm{s}$ njihovim pravnim i ekološkim posljedicama, stavili su stare sisteme pod pritisak. Stoga je u PJ Vlasenica i PJ Han Pijesak uspostavljen eTerraSoft softver, koji je ujedno i zvanični softver $\mathrm{u}$ cijeloj Republici Srpskoj. Realizovan je 2013. godine, međutim 2015. godine se zvanično prelazi na eTerraSoft. Od tada je planirano da se sve promjene, i grafičke, i numeričke, i u operatu, i na DKP-u provode isključivo u eTerraSoft-u. Tim povodom Republička uprava za geodetske i imovinsko-pravne poslove organizovala je obuku zaposlenih u svim područnim jedinicama širom Republike Srpske.

Što se tiče opremljenosti instrumentima, možemo zaključiti da nije na zadovoljavajućem nivou ali može da isprati obim posla obje područne jedinice. Naime, PJ Vlasenica raspolaže sa jednom totalnom stanicom marke Topcon - GTS 212 i jednim GPS uređajem marke CHC „X900+ “. Kako je totalna stanica u jako lošem stanju uglavnom se koristi GPS uređaj prilikom geodetskog snimanja, osim u slučajevima kada objekti ili vegetacija onemogućavaju prijem signala. PJ Han Pijesak raspolaže sa jednom totalnom stanicom marke Topcon - GTS $220 \mathrm{i}$ nivelirom Carl Zeiss Jena NIO25. Pored toga služba posjeduje i dva nivelira sa kompenzatorom i može se nažalost reći da su navedeni instrumenti uglavnom dovoljni za potrebe ove opštine.

Zaposlenim je dostupan ortofoto za cijelu Republiku Srpsku i pruža im velike olakšice u svakodnevnom radu i snalaženju. U toku izlaganja podataka, strankama je obezbijeđen uvid objedinjenih alfanumeričkih i grafičkih podataka sa prikazom digitalnog plana i preklopljenim ortofoto snimkom u cilju lakše orjentacije i prepoznavanja detalja. U praksi se pokazalo da se i stranke znatno lakše snalaze upravo sa ortofoto snimcima nego sa digitalnim katastarskim planovima.

Kada je riječ o privatnim geodetskim agencijama, na području opštine Vlasenica, kao i na području opštine Han Pijesak, ne postoji registrovana nijedna takva agencija. Najčešće se angažuje agencija za geodetske poslove Georad iz Trebinja. Ova agencija je dugogodišnji najtraženiji stručni tim u Hercegovini za obavljanje svih vrsta geodetskih usluga (uplanjivanje nepokretnosti, ekspoprijacija, izrada situacionih planova, etažiranje, cijepanje-dioba nepokretnosti, izrada katastra komunalnih uređaja, inženjerska geodezija, sudska vještačenja).

\section{ZAKLJUČAK}

Analizom razvoja održavanja državnog premjera i katastra nepokretnosti na području opština Vlasenica i Han Pijesak može se zaključiti da je taj proces nedovoljno razvijen, iako je u ekspanziji i primjena informacionih tehnologija i računarskih sistema.

Razloge za ovo prije svega treba tražiti u problemima koji nastaju zbog nedostataka pravilnika koji bi definisali komplikovane procedure koje se svakodnevno javljaju u ovom dinamičnom procesu. Takođe, još uvijek nisu zadovoljeni postavljeni standardi i ciljevi koji se odnose na obezbjeđenje veće tačnosti i pouzdanosti podataka, poboljšanje usluga korisnicima, povezivanje baza podataka u jedinstven sistem.

U političkoj opštini Vlasenica digitalni katastarski plan je izrađen za deset katastarskih opština, dok se za preostalih osam izrada planira u bliskoj budućnosti. Digitalni katastarski plan na području političke opštine Han Pijesak pokriva čak $83 \%$ teritorije, dok je za preostali dio opštine izrada u toku. Za obje opštine kao podloga za izradu DKP-a korišteni su originalni podaci premjera, zbog čega su u postupku svog nastajanja pretrpjeli manji stepen grešaka.

S obzirom na procenat urađenog digitalnog katastarskog plana, broj neriješenih zaostalih predmeta, kao i ažurnost u riješavanju svakodnevno primljenih zahtjeva, a imajući $\mathrm{u}$ vidu obrazovnu strukturu zaposlenih u obje opštine, može se reći da je bolje stanje premjera u katastru $u$ političkoj opštini Han Pijesak.

Izgradnjom Geoinformacionog sistema Republičke uprave za geodetske i imovinskopravne poslove (GIS RGU RS) i infrastrukture geoprostornih podataka (IGPRS) stvaraju se pretpostavke za uspostavu modernog katastra kao osnovnog informacionog sistema koji će poslužiti kao osnova za izgradnju informacionih sistema u drugim oblastima koje koriste geoprostorne podatke.

\section{LITERATURA}

[1] Zakon o premjeru i katastru Republike Srpske ("Službeni glasnik Republike Srpske", broj 06/12).

[2] Pravilnik za održavanje premjera i katastra zemljišta ("Službeni glasnik Republike Srpske", broj 17/09).

[3] Cvijović Č, "Procedure i postupci u katastru nepokretnosti", Visoka građevinsko geodetska škola, Beograd, 2009.

\section{Kratka biografija:}

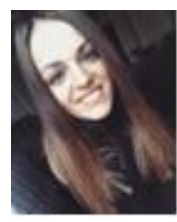

Aleksandra Deurić rođena je 1994. godine u Vlasenici. Gimnaziju opšti smjer u Vlasenici završila je 2012. godine. Diplomski rad iz oblasti katastra na Fakultetu tehničkih nauka, odbranila je 2016. godine

(kontakt: mail: aleks.deuric@gmail.com)

Goran Marinković rođen je u Vlasenici 1968. god. Doktorsku disertaciju na Fakultetu tehničkih nauka iz oblasti geodezije odbranio 2015.god.

(kontakt: mail: goranmarinkovic@uns.ac.rs) 